\title{
26472 - IS HBA1C A MARKER FOR POOR OUTCOME AFTER CABG IN UNDIAGNOSED DIABETICS?
}

\section{Carmen Kummer MD, Claude Laflamme, MD FRCPC; Jenny Lam-mcculloch, MSc; Sunnybrook And Women's College Health Sciences Centre, Toronto, ONTARIO, Canada}

INTRODUCTION: Diabetes mellitus is associated with poorer outcomes after coronary artery bypass grafting (CABG).[1,2] In the undiagnosed diabetic population, asymptomatic hyperglycemia (Fasting plasma glucose $; 126 \mathrm{mg} / \mathrm{dl}$ ) has been reported as a predictor for higher rate of cardiovascular death [3] and greater morbidity/mortality after cardiac surgery.[4] It remains unclear whether glycosylated hemoglobin (HbA1c) could be considered a surrogate marker for morbidity/mortality after CABG in nondiabetics. The objective of this study was to determine if high levels of HbA1c $(; 0.07)$ in undiagnosed diabetics is related to adverse events after CABG.

METHODS: The study included a review of 758 patients who had undergone primary CABG between November 15, 2004 and November 15, 2005. Emergency surgeries, redo operations and combined procedures were excluded. Preoperative demographic and 13 medical and surgical characteristics as well as 8 postoperative complications were recorded. Differences between binary outcomes were calculated using Chi-Square. Continuous data were analyzed by using Mann Whitney's U Test to determine differences among groups.

RESULTS: Out of 758 patients, 210 (27.7\%) were known to be diabetic. Among the 548 subjects considered to be non-diabetic, 393 had a preoperative HbA1c value in their charts. The study population was comprised of 3 groups: known diabetics $(\mathrm{N}=210)$, undiagnosed diabetics (preoperative HbA1c ; 0.07; $\mathrm{N}=36$ ) and non-diabetics (preoperative HbA1c $\quad 0.07 ; \mathrm{N}=357$ ). There were no differences between groups for all demographic variables. Medical history and pump time were also similar.

DISCUSSION: There is a strong association between hyperglycemia and increased morbidity/mortality after CABG. Among diabetics, normal HbA1c is a reliable measure of chronic glycemic control. Elevated $\mathrm{HbA} 1 \mathrm{c}$ has been associated with increased risk of cardiovascular events [5] and new-onset of heart failure in diabetic patients.[6] In type 2 diabetics, HbA1c was associated to cognitive impairment after CABG.[7] HbA1c of 7\%, or greater, was a predictor of length of stay in hospital ; 6 days.[8] Whether high levels of $\mathrm{HbAlc}$ in undiagnosed diabetics undergoing $\mathrm{CABG}$ can lead to poor outcomes is still unclear. We demonstrated that after $\mathrm{CABG}$, the infection rate was significantly greater in the undiagnosed diabetic group with high $\operatorname{HbA} 1 \mathrm{c}(\mathrm{p}=0.03)$ and that there is a trend showing a higher incidence of stroke in this group. These preliminary results suggest that HbA1c may be marker for poor outcome after CABG in undiagnosed diabetic patients. REFERENCES: [1] Ann Thorac Surg 1999; 67: 1205-1208; [2] Ann Thorac Surg 1999; 67: 1045-1052; [3] Diabetes Care 1997; 20: 163-169; [4] Circulation 2005; 112: 23972402; [5] Ann Intern Med 2004; 141: 421-431; [6]. Practice 2004 10(6):467-471; [7] J Thorac Cardiovasc Surg. 2005 Mar; 129(3): 576-583; [8] Hear Dis. 2001 Mar-Apr; 3(2): 77-79. 


\begin{tabular}{|c|c|c|}
\hline $\begin{array}{c}\text { Postoperative } \\
\text { Complications }\end{array}$ & $\begin{array}{c}\text { Non-Diabetic } \\
\text { HbA1c }<0.07(\mathrm{~N}=357)\end{array}$ & $\begin{array}{c}\text { Non-Diabetic } \\
\text { HbA1c }>0.07(\mathrm{~N}=36)\end{array}$ \\
\hline New AFIB & $84(23.5 \%)$ & $7(19.4 \%)$ \\
\hline Dialysis & $1(0.3 \%)$ & $0=0 \%$ \\
\hline Infection & $8(2.2 \%) 0(0.0 \%)$ & $3(8.3 \%)$ \\
\hline Stroke & $10(2.8 \%)$ & $3(8.3 \%)$ \\
\hline Mechanical Vent (hrs) & $15.9 \pm 59.5$ & $26.2 \pm 81.7$ \\
\hline LOS ICU (hrs) & $49.2 \pm 94.7$ & $67.9 \pm 129.7$ \\
\hline 30 Day Mortality & $11(3.1 \%)$ & $0(0.0 \%)$ \\
\hline Low Output Syndrome & $67(18.3 \%)$ & $7(19.4 \%)$ \\
\hline
\end{tabular}

